\title{
Common Peroneal Nerve Palsy and Long-Lasting Ropivacaine Duration After Inferolateral Genicular Nerve Block: A Case Report
}

\author{
Poupak Rahimzadeh, MD${ }^{1}$, Kamran Mahmoudi, MD², and Seyed Hamid Reza Faiz, MD ${ }^{1}$
}

\section{ABSTRACT}

This case report introduces a 43-year-old woman who presented with left knee pain due to knee osteoarthritis. She developed a long-lasting nerve block with ropivacaine, plus common peroneal nerve palsy and foot drop following a genicular nerve block.

Key words: Ropivacaine, knee osteoarthritis, genicular nerve block, foot drop
Osteoarthritis $(O A)$ is one of the most common diseases afflicting human beings, and the knee is the most common joint affected by osteoarthritis $(1,2)$. A variable treatment for OA can be classified into 3 groups: drug, nonsurgical, and surgical therapies. The sequence of treatment applications begins with drug therapies and ends with surgical therapies (3-5). Nonsurgical interventions for pain control of knee osteoarthritis include weight loss, exercise, changes in daily activities, physiotherapy, nonsteroidal anti-inflammatory drugs (NSAIDs), and analgesics; intraarticular injections such as corticosteroids, hyaluronic acid, growth hormone, and dextrose; and performance of pulsed or conventional radiofrequency (6-9).

Radiofrequency (RF) ablation of the genicular nerves, a recently introduced option, appears to be safe and effective for treating intractable knee OA pain, according to several studies $(10,11)$. Generally,

From : ${ }^{1}$ Associate Professor of Anesthesiology, Pain Research Center, Rasoul Akram Hospital, Iran University of Medical Sciences, Tehran, Iran. ${ }^{2}$ Pain Fellow, Pain Research Center, Rasoul Akram Hospital, Iran University of Medical Sciences, Tehran, Iran.

Author for correspondence: Poupak Rahimzadeh, MD

Address: Pain Research Center, Rasoul, Akram Hospital, Tehran, Iran

E-mail: poupak_rah@hotmail.com a diagnostic genicular nerve block (GNB) with local anesthetic is performed before RF genicular ablation, and a successful response to GNB is considered to indicate the need for RF genicular ablation (12). In this case report, we present a woman with knee OA who developed a long-lasting block with ropivacaine and common peroneal nerve palsy and foot drop following genicular block.

\section{CASE PRESENTATION}

A 43-year-old healthy woman was admitted to the operating room of the HazratRasul-e-Akram hospital of Tehran. She complained of chronic left knee pain. At the radiologic evaluation, the patient was diagnosed as having grade II osteoarthritis due to a small osteophyte presence and joint space narrowing. The patient was determined to be a candidate for knee prolotherapy and genicular nerve injection. After providing informed consent, the patient was placed in a supine position with a $10^{\circ}$ to $15^{\circ}$ knee flexion. Under sterile conditions and ultrasound guidance using a linear probe of 13 to $16 \mathrm{~Hz}$ (Sonosite, Bothell, WA), $5 \mathrm{~mL}$ of ozone $20 \mu \mathrm{g}$ plus $3 \mathrm{~mL}$ of dextrose $25 \%$ was injected intraarticularly with a superolateral approach. Then the transducer was placed parallel to the long femur shaft and moved up or down to identify the epicondyle of the long bone. Also, inferolateral genicular nerve scan performed over the tibial 


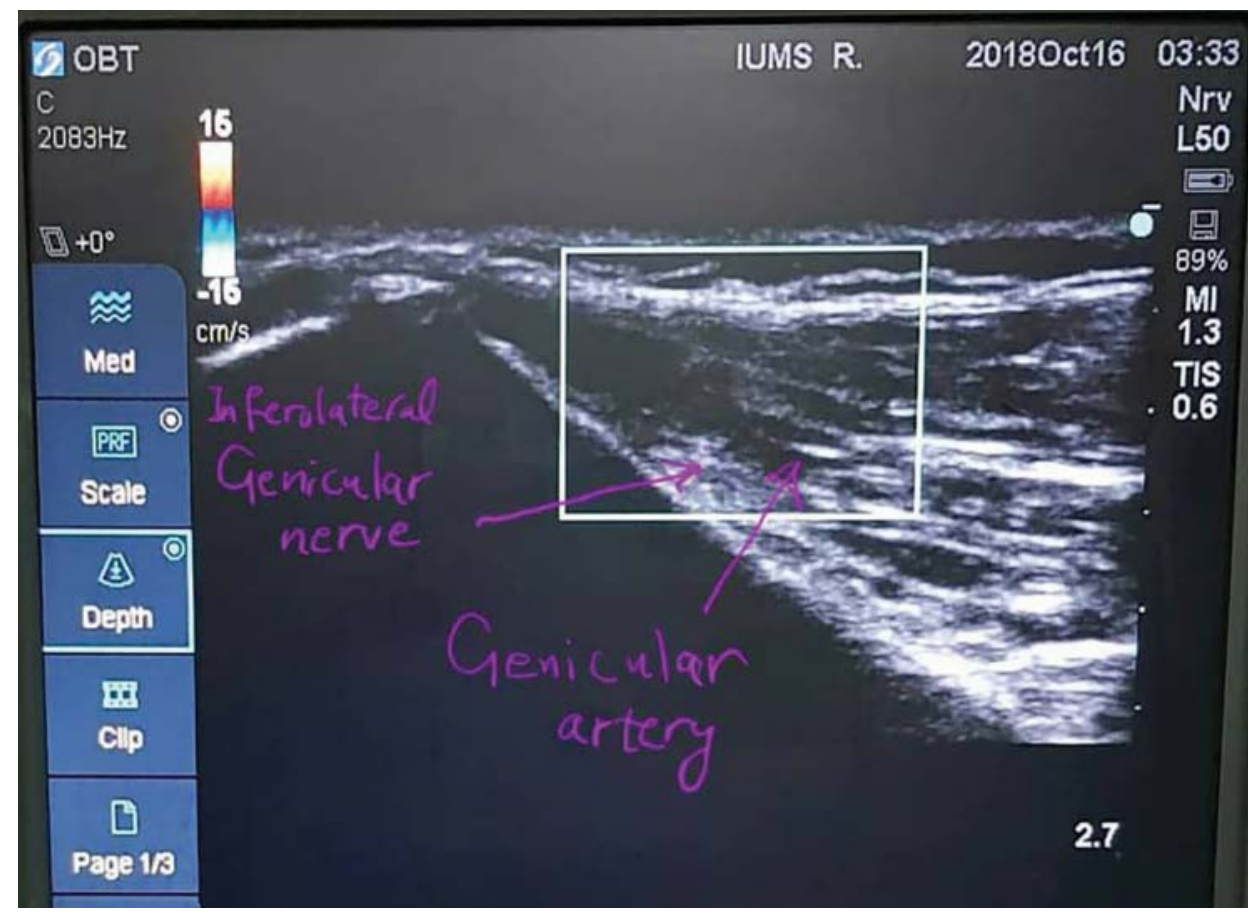

Fig. 1. Ultrasound image of Inferolateral Genicular nerve.

bone. The genicular arteries were identified near the periosteal areas and confirmed by color Doppler ultrasound. A genicular nerves target point was identified next to each genicular artery (superior lateral, superior medial, inferior lateral, inferior medial). Then a 1.5-inch, 22-gauge needle was advanced, using an out-of-plane approach with the needle trajectory adjusted under real-time ultrasound guidance to lie in proximity to the target. After proper needle tip placement was confirmed, a $2.5 \mathrm{~mL}$ solution containing 0.2 $\%$ preservative-free ropivacaine (Molteni, Italy) and $10 \mathrm{mg}$ of triamcinolone (Exir, Iran) was injected for each genicular nerve.

About 20 minutes after the genicular block, the patient reported a decrease of force of the left greater toe. Gradually the weakness became more severe and expanded into the whole territory of the common peroneal nerve, and 5 minutes later, foot drop occurred. Immediately the patient was examined and underwent an ultrasound scan, and there was no effusion or hematoma around the nerve. The patient asked for resting at home while close observation via phone call was performed. The next day the patient underwent ultrasound and was scanned for any possible effusion or hematoma; results were negative.
About 21 hours after the injection, the symptoms gradually decreased, and about 26 hours after injection, the symptoms resolved completely; motor function and gait became normal without any sequela. We monitored the patient for the next 2 months and she had normal gait without any deficit in the common peroneal nerve territory. Figure 1 shows the ultrasound image of the inferolateral genicular nerve.

\section{DISCUSSION}

In this case report, the duration of peak action of ropivacaine was 21 hours, and complete recovery was 26 hours; that is similar to the results of the Keramidas et al (13) study on digital nerve blocks, in which the mean duration of postoperative anesthesia was 21.5 hours. In that study, however, they used $2.5 \mathrm{~mL}$ of $0.75 \%$ ropivacaine solution; we used 2.5 $\mathrm{mL}$ of $0.2 \%$ ropivacaine solution, so we achieved a prolonged effect with lower concentration and volume. In the study by Andersen et al (14), the mean duration of the adductor canal block using $20 \mathrm{~mL}$ of ropivacaine $0.5 \%$ was 19.3 hours, but the concentration of solution was not similar with our patient. In Gonzalez et al (15), 4 genicular nerves (superior medial, superior lateral, inferior medial, and inferior lateral) 
were blocked with $4 \mathrm{~mL}$ of bupivacaine $0.25 \%$; they reported a lower pain score and rescue analgesia findings, which is similar to our study with respect to the decrease in pain score; however, we observed a prolonged anesthesia with diluted ropivacaine in the common peroneal nerve, which is located next to the genicular nerve.

\section{CONCLUSION}

Local anesthetics, especially those with long-acting effects, may have more prolonged anesthesia than expected. In addition, due to the proximity of the inferolateral genicular nerve approach to the common peroneal nerve, the blockade could impact adjacent structures. This possibility limits any approach to the inferolateral genicular nerve.

\section{ACKNOWLEDGMENT}

The study was approved by the ethics committee at Iran University of Medical Sciences. The authors thank the Rasoul Akram Clinical Research Development Center (RCRDC) for its technical and editorial assistance.

\section{DISCLOSURE}

The authors declare no conflicts of interest in this work 


\section{REFERENCES}

1. Waldman SD. Pain Management. Philadelphia, Elsevier, 2011: pp. 384-395.

2. Nguyen C, Lefèvre-Colau MM, Poiraudeau S, Rannou F. Evidence and recommendations for use of intra-articular injections for knee osteoarthritis. Ann Phys Rehabil Med 2016; 59:184189.

3. Chang KV, Hung CY, Aliwarga F, Wang TG, Han DS, Chen WS. Comparative effectiveness of platelet-rich plasma injections for treating knee joint cartilage degenerative pathology: A systematic review and meta-analysis. Arch Phys Med Rehabil 2014; 95:562-575.

4. Gupta A, Huettner DP, Dukewich M. Comparative effectiveness review of cooled versus pulsed radiofrequency ablation for the treatment of knee osteoarthritis: A systematic review. Pain Physician 2017; 20:155-171.

5. Rahimzadeh P, Imani F, Faiz SHR, Entezary SR, Zamanabadi $\mathrm{MN}$, Alebouyeh MR. The effects of injecting intra-articular platelet-rich plasma or prolotherapy on pain score and function in knee osteoarthritis. Clin Interv Aging 2018; 13:73-79.

6. Imani $F$, Rahimzadeh P. Interventional pain management according to evidence-based medicine. Anesth Pain Med 2012; $1: 235-236$

7. Kesikburun S, Yaşar E, Uran A, Adigüzel E, Yilmaz B. Ultrasound-guided genicular nerve pulsed radiofrequency treatment for painful knee osteoarthritis: A preliminary report. Pain Physician 2016; 19:E751-E759.

8. Rahimzadeh P, Imani F, Faiz SH, Entezary SR, Nasiri AA, Ziaeefard M. Investigation the efficacy of intra-articular prolotherapy with erythropoietin and dextrose and intra-articular pulsed radiofrequency on pain level reduction and range of motion improvement in primary osteoarthritis of knee. J Res Med Sci
2014; 19:696-702.

9. Kim SB, Kwon DR, Kwak H, Shin YB, Han HJ, Lee JH, Choi SH. Additive effects of intra-articular injection of growth hormone and hyaluronic acid in rabbit model of collagenase-induced osteoarthritis. J Korean Med Sci 2010; 25:776-780.

10. Sari S, Aydin ON, Turan Y, Özlülerden P, Efe U, Kurt Ömürlü I. Which one is more effective for the clinical treatment of chronic pain in knee osteoarthritis: Radiofrequency neurotomy of the genicular nerves or intra-articular injection? Int J Rheum Dis 2018; 21:1772-1778.

11. Kirdemir P, Çatav S, Alkaya Solmaz F. The genicular nerve: Radiofrequency lesion application for chronic knee pain. Turk $\mathrm{J}$ Med Sci 2017; 47:268-272.

12. Qudsi-Sinclair S, Borrás-Rubio E, Abellan-Guillén JF, Padilla Del Rey ML, RuizMerino G. A comparison of genicular nerve treatment using either radiofrequency or analgesic block with corticosteroid for pain after a total knee arthroplasty: A doubleblind, randomized clinical study. Pain Pract 2017; 17:578-588.

13. Keramidas EG, Rodopolou SG. Ropivacaine versus lidocaine in digital nerve block. Plast Reconstr Surg 2007; 119:2148-2152.

14. Andersen JH, Jaeger $P$, Sonne TL, Dahl JB, Mathiesen $O$, Grevstad U. Clonidine used as a perineural adjuvant to ropivacaine, does not prolong the duration of sensory block when controlling for systemic effects: A paired, blinded, randomized trial in healthy volunteers. PLOS One 2017; 12:e0181351.

15. Gonzalez Sotelo V, Macule F, Minguell J, Berge R, Franco C, Sala-Blanch $X$. Ultrasound-guided genicular nerve block for pain control after total knee replacement: Preliminary case series and technical note. Rev Esp Anestesiol Reanim 2017; 64:568-576. 